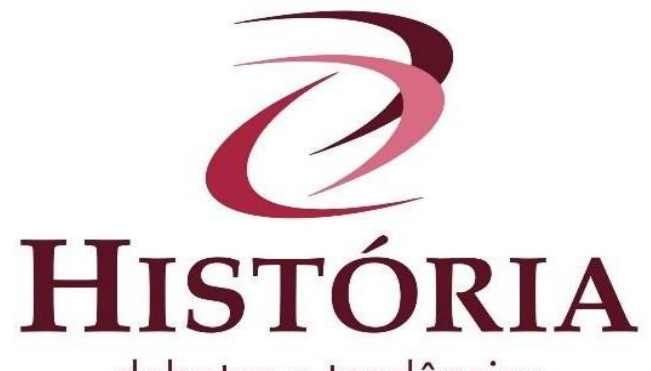

\title{
A história intelectual e a virada ontológica na antropologia
}

\section{Intellectual history and the ontological turn in anthropology}

\section{La historia intelectual y el giro ontológico en la antropología}

\section{Carlos Henrique Armani*}

\begin{abstract}
Resumo: O presente artigo pretende mostrar uma investigação sobre a contribuição que a virada ontológica na antropologia contemporânea pode proporcionar para a história intelectual. Trata-se de pensá-la como uma resposta à virada linguística ao se evocar o primado ontológico conferido aos existentes, incluindo não humanos, o que reforça seu caráter materialista, por vezes antinarrativista e antitextualista. O artigo divide-se em três partes: a primeira apresenta algumas características da história intelectual no interior da virada linguística e para além dela; a segunda apresenta algumas ideias da virada ontológica na antropologia, consubstanciadas na antropologia simétrica, no perspectivismo ameríndio e na antropologia da natureza; por fim, lança mão de um exemplo empírico da história intelectual no Brasil que pode permitir uma leitura da obra como presença de duas ontologias: a naturalista e a animista. Trata-se da obra Os sertões, de Euclides da Cunha.
\end{abstract}

Palavras-chave: Antropologia. História intelectual. Virada ontológica.

\begin{abstract}
In this article we intend to present an investigation on the contribution that the ontological turn in contemporary anthropology can provide to intellectual history. It is thought as a response to the linguistic turn, especially by the ontological primacy given to existing ones, including nonhumans, which reinforces its antinarrativist and anti-textual materialist character. The work was divided into three parts: in the first, we present some features of intellectual history within and beyond the linguistic turn; in the second part, we present some ideas of the ontological turn in anthropology, embodied in symmetrical anthropology, Amerindian perspectivism and anthropology of nature; Finally, we use an empirical example of intellectual history in Brazil that can allow a reading of the work as the presence of two ontologies: the naturalism and the animism. It is the work Rebellion in the Backlands, by Euclides da Cunha.
\end{abstract}

Keywords: Anthropology. Intellectual history. Ontological turn.

Resumén: En este artículo pretendemos presentar una investigación sobre la contribución que el giro ontológico en la antropología contemporánea puede hacer a la historia intelectual. Se considera que esto responde a el giro lingüístico, especialmente por la primacía ontológica dada a los existentes, incluidos los no humanos, que refuerza su carácter materialista a veces antinarrativista y antitextual. El artículo se dividió en tres partes: en la primera, presentamos algunas características de la historia intelectual dentro y más allá del giro lingüístico; En la segunda parte, presentamos algunas ideas del giro ontológico en la antropología, consustanciadas en la antropología simétrica, el perspectivismo amerindio y la antropología de la naturaleza; Finalmente, usamos un ejemplo empírico de la historia intelectual en Brasil que puede permitir una lectura del trabajo como la presencia de dos 
ontologías: el naturalismo y el animismo. Es la obra Os sertões, de Euclides da Cunha. Palabras clave: Antropología. Giro ontológico. Historia intelectual.

A espiritualidade do etnocídio é a ética do humanismo

(Pierre Clastres)

Pretendemos apresentar, neste artigo, uma investigação sobre a contribuição que a virada ontológica na antropologia contemporânea pode proporcionar para a história intelectual. Trata-se de pensá-la como uma resposta a certas tendências formalistas da virada linguística, especialmente pelo primado ontológico conferido aos existentes, incluindo não humanos, o que reforça seu caráter materialista, por vezes antinarrativista e antitextualista. Ao longo dos últimos 20 anos, algumas tendências de pensamento reivindicam um retorno às coisas do mundo em seu caráter de tangibilidade e de presença, bem como uma retomada de modos de existência que foram subordinados ao naturalismo como ontologia primeira. É para essas tendências que nos direcionamos a seguir, de modo que possamos destacar sua importância para repensar a história intelectual. $\mathrm{O}$ artigo foi dividido em três partes: na primeira, apresentamos algumas características da história intelectual no interior da virada linguística e para além dela; na segunda parte, apresentamos algumas ideias da virada ontológica na antropologia, consubstanciadas na antropologia simétrica, na antropologia da natureza e no perspectivismo ameríndio; por fim, lançamos mão de um exemplo empírico da história intelectual no Brasil que pode permitir uma leitura da obra como presença de duas ontologias: a naturalista e a animista. Trata-se da obra Os sertões, de Euclides da Cunha.

\section{História intelectual, virada linguística e ontologia}

Com certa frequência, a expressão "ontologia" aparece como sinônimo de uma essência. Ao falar de uma virada ontológica, não queremos reafirmar um reencontro com determinadas essências intocadas pela temporalidade, pela transformação, pelo devir; ao contrário, trata-se de reconhecer certas propriedades dos existentes que se relacionam como tal por meio das forças de embate que se encontram no mundo e que exercem pressão sobre a linguagem, constituindo-se em condições de historicidade que prefiguram a escrita da história. É possível descrever e representar determinadas propriedades de acontecimentos 
ou processos do passado, tais como Renascimento, Revolução Francesa, Revolta da Vacina, Guerra de Canudos, entre outros, sem que tenhamos de chegar a uma essência do que seria uma revolução, uma revolta, uma guerra ou um renascimento. Historicizar as propriedades de existentes do passado não significa que estejamos essencializando-os, ainda que estejamos ontologizando-os.

Reconhecer a importância da ontologia remete para o velho problema da relação entre linguagem e mundo. Os historiadores, em seu processo de pesquisa e escrita da história, lidam constantemente com as pressões que a experiência e que a linguagem exercem sobre sua prática, sem que possam, muitas vezes, distinguir uma de outra (ANKERSMIT, 2001). A virada linguística foi uma das marcas do pensamento filosófico do século XX. Seu impacto não poderia ser indiferente aos historiadores, que perceberam o quanto seu objeto depende de uma mediação que, em última análise, é linguagem. Aforismos e afirmações como "os limites da minha linguagem significam os limites do meu mundo" ou "a linguagem é a morada do ser", respectivamente de Wittgenstein e de Heidegger, expressaram modos de pensar que repercutiram de maneira contundente no mundo acadêmico das humanidades. Tanto na mais dura ortodoxia materialista que negava qualquer realidade fora dos fatos, dos processos e das estruturas de uma materialidade préexistente à linguagem, quanto entre aqueles que afirmaram não ser o mundo senão linguagem (ao menos, o mundo do sentido), a virada linguística marcou seu terreno no âmbito das discussões acerca de nosso acesso à realidade.

Contudo, o sucesso da virada linguística contribuiu para um abandono paulatino da ontologia em prol da epistemologia, ou pelo menos, de algumas ontologias que foram relegadas ao terreno metafísico da história. Questões de relevância ontológica, tais como as propriedades de determinados eventos e processos do passado, passaram a ser compreendidas como recortes de realidade que seriam entendidos por meio de conceitos e métodos apropriados para sua apreensão, sem que se perseguisse uma essência do passado ou um padrão necessário de sucessão de seus acontecimentos. A cada recorte do passado, a sua metodologia e os seus conceitos apropriados. Feita a operação que permitisse adequar da melhor maneira possível os dois últimos ao primeiro, o conhecimento histórico estaria realizado em termos científicos. Basicamente, uma redução do nível da realidade à sua possibilidade descritiva e representativa por meio do método. O esquecimento do ser não se devia somente a uma suposta ignorância dos diversos entes que as ciências traziam à tona, mas também ao próprio esforço da ciência e, com ela, da ciência histórica, de purificar o passado de suas propriedades "essencializadas" ou "metafísicas", como se tais predicados 
fossem sinônimos de ontologia.

O outro problema do abandono da ontologia tem a ver com esse desdobramento da linguagem sobre ela mesma, com o reconhecimento de que uma boa parte, senão a totalidade, dos problemas filosóficos seria resolvida "reformando a linguagem ou compreendendo melhor o que usamos no presente" (RORTY, 1990, p. 50). Quer dizer, para que pudéssemos conhecer algo, deveríamos antes pensar a natureza da linguagem desse algo que se pretenderia dizer. Santos, em uma apresentação da biografia e da obra de Bertrand Russell, indica com precisão essas mudanças nos rumos do pensamento filosófico ocidental do século XX:

\footnotetext{
Pretendendo-se saber qual a natureza das coisas, é necessário procurar conhecê-las; a questão de saber o que as coisas são é, pois, inseparável da questão de saber como se conhecem as coisas como sendo o que são, e particularmente, da questão de saber qual a garantia de que as coisas são o que se diz que elas são ao se pretender conhecê-las. Em suma, o problema metafísico (o que as coisas são) seria inseparável do problema epistemológico (o que garante a verdade de um suposto conhecimento) das coisas e como um conhecimento verdadeiro delas é possível (1978, p. VI).
}

A história intelectual não ficou imune a essas transformações, sobretudo porque, com a virada linguística, os principais contornos que a história intelectual assumiu restringiam-na a uma abordagem que ora pendia para a linguística, ora para a semântica, ora para a hermenêutica. É verdade que diferentes propósitos marcaram as variações da história intelectual, tais como a história dos conceitos, a história das ideias, a história dos discursos, entre outros que, dependendo do enfoque, tinham mais ou menos interesse na relação da linguagem com as coisas do mundo fora do texto. Intencionalistas como Quentin Skinner e John Pocock, passando por historiadores mais sensíveis à história social, como Dominick Lacapra, pensaram seus trabalhos no horizonte teórico da virada linguística. No primeiro caso, por via de uma aproximação a Austin e Saussure; no segundo, por uma aproximação à hermenêutica heideggeriana e à desconstrução derridiana. Em comum, a crença de que seria o contexto de linguagem usado por determinados agentes do passado o objeto por excelência da história intelectual. No caso de Lacapra (1983), o autor manteve uma relação mais sólida com o mundo da experiência, ao mencionar o que o historiador intelectual, ao se deparar com seu objeto de estudo - em seu exemplo, textos clássicos - deveria levar em consideração. A saber, tanto o caráter documental do texto, que o situa nos termos das dimensões literais ou factuais envolvendo a referência à realidade empírica e transmitindo informações sobre ela (o que Ankersmit definiria como o nível da descrição), como também 
o caráter de obra da obra, o qual suplementa a realidade, adicionando ou subtraindo algo dela (o que seria o nível mais profundo da representação na condição de ser sobre o passado, mais do que simplesmente referi-lo - novamente, nos termos de Ankersmit).

Não seria correto identificar historiadores como Lacapra, Skinner, Pocock e mesmo Hayden White como relativistas que teriam abandonado todo seu compromisso com o princípio de realidade. Há uma questão de fundo que diz respeito à relação entre continuidade e descontinuidade, entre narrativa e mundo real, que é, de modo mais ou menos explícito conforme o autor, tratada por eles (CARR, 1991; 2014). Nesse sentido, não seria o caso de afirmar que tais autores abandonaram o compromisso de pensar a realidade do passado, ou os modos como a realidade do passado nos afeta no presente. Contudo, mesmo que Lacapra tenha sido mais cauteloso na relação entre linguagem e mundo, especialmente em suas publicações mais recentes, que leva em consideração a relação da história com não humanos (LACAPRA, 2018), ${ }^{\mathrm{i}}$ o fato é que a história intelectual tem se mantido fiel a uma teoria do conhecimento que pouco agrega em termos de existentes que não se restringem à linguagem, ou que se manifestam na linguagem como meros efeitos de realidade.

$\mathrm{O}$ que nos propusemos a apresentar na sequência como a virada ontológica na antropologia vem ao encontro de um esforço de pensar a história intelectual e as obras com as quais trabalhamos capazes de manifestar determinados modos de existência em que as propriedades dos existentes do mundo sofrem certa variação que não as reduzem a um universo de relações que separa natureza, sociedade, linguagem e ser. Não se trata, como poderemos notar, de uma presença no sentido de reflexo de determinados objetos do mundo na escrita, como certo empirismo ingênuo poderia sugerir. Trata-se de verificar em que medida podemos ler certas obras de determinados autores e, com ela, trazer à presença outra presença de mundo que se manifesta na linguagem, mas que não se restringe a ela.

\section{A virada ontológica na antropologia}

A virada ontológica no pensamento contemporâneo pode ser colocada como uma resposta à virada linguística. Não há um texto canônico sobre o assunto, nem uma corrente específica de pensamento que possa ser seu paradigma mestre. Nas palavras de Clemens (2013, p. 57), o realismo especulativo ou a ontologia orientada a objetos (alguns dos nomes da virada ontológica) podem ser aproximados entre si a partir de três características-chave: uma hostilidade ao antropocentrismo kantiano, a convicção da necessidade de um retorno 
aos objetos e às coisas em si mesmas e, por fim, a necessidade de se desenvolver novos modos (e desafios) de pensar. Como veremos, na antropologia, que escolhemos para este trabalho, há reflexões que convergem de modo bastante original para essas características, especialmente a crítica ao antropocentrismo através de uma via que reconhece diversos modos de distribuir os existentes no mundo.

A primeira das características-chave apontadas acima, a saber, o antropocentrismo, tem sido um problema para a antropologia. No contexto em que colocamos esse debate, Descola afirma que é difícil conduzir-se como se os não humanos não estivessem em todos os lugares da vida social, tais como um macaco com o qual nos comunicamos em um laboratório, a alma de um inhame que visita em sonhos aquele que o cultiva, um adversário eletrônico a ser derrotado no xadrez ou um boi tratado como substituto de uma pessoa em uma prestação cerimonial (DESCOLA, 2012, p. 21). Para o autor, a análise das interações entre os habitantes do mundo já não pode limitar-se somente ao setor das instituições que regem a vida dos homens, como se aquilo que se decretasse exterior a eles não fosse mais do que um conglomerado anômico de objetos a espera de sentido e de utilidade (DESCOLA, 2012, p. 21).

A seguir, apresentamos algumas tendências do pensamento antropológico contemporâneo que convergem para a virada ontológica no pensamento contemporâneo. As perspectivas escolhidas e acolhidas para tal recenseamento são a antropologia simétrica, o perspectivismo e a antropologia da natureza, que reabilitam ontologias pouco usuais diante de uma antropologia produzida em contextos multiculturais. Em um sentido mais abrangente, podemos afirmar que tais práticas têm sido desenvolvidas por diversos antropólogos, entre os quais destacamos Eduardo Viveiros de Castro, Tânia Lima, Manuela Carneiro da Cunha, Philippe Descola, Bruno Latour, Louis Dumont, Marshall Sahlins, sem falar daqueles que são antropólogos de outro modo que não nos termos do Ocidente, como Dawi Kopenawa e Ailton Krenak, a despeito das diferenças entre eles e das diferentes terminologias que mobilizam. Um dos nomes para essa antropologia, ainda que tenha começado a "exibir certo desbotamento" (SÁ JÚNIOR, 2014, p. 9), é simetria. Ousamos denominar a simetria como uma atitude (e não um paradigma) para pensar não somente sujeitos e objetos em uma relação de híbridos em que suas posições de sujeitos e de objetos se alternam ou se formam como quase-sujeitos ou quase-objetos, como também um modo de tratar, como diz Viveiros de Castro, com a mesma dureza conceitual, certos recortes de realidade que tendemos a domesticar para não tocar em sua ontologia, em outras palavras, antropologizar o "centro" e não apenas a "periferia" de nossa cultura (VIVEIROS DE 
CASTRO, 2008, p. 46). Sá Júnior acrescenta que a antropologia simétrica “pretende conferir aos nativos tradicionalmente assim designados, notadamente os indígenas americanos, a capacidade de elaborar teorias acerca de suas próprias sociedades e a de seus visitantes" (2014, p. 30). Essa definição menos restritiva de simetria pode servir para os três enfoques dos quais tratamos nesse texto. Contudo, optaremos por utilizá-la para nos referir ao pensamento de Bruno Latour, que a tem empregado com mais frequência.

Segundo Latour, a constituição moderna criou uma espécie de assimetria entre diversos entes que habitam o mundo, de modo a tornar incompatíveis suas qualidades ontológicas, ou seja, seus modos de ser e de se relacionar entre si. De acordo com o autor, há, pelo menos, quatro grandes repertórios que se tornaram campos distintos de atividade e cuja "contrarrevolução copernicana", promovida pela simetria, coloca-os em uma relação em que sua condição de quase-sujeito ou quase-objeto (nos dois casos, tanto humanos quanto não humanos) demanda um tratamento em termos de rede.

O primeiro repertório trata da realidade exterior de uma natureza da qual não somos mestres, que existe fora de nós e que não conta nem com nossas paixões, nem com nosso desejo, ainda que sejamos capazes de mobilizá-la e de construí-la (LATOUR, 1994, p. 87). O segundo repertório trata do laço social, daquilo que liga os humanos entre si, das paixões e desejos que nos agitam, das forças personificadas que estruturam a sociedade (idem, ibidem, p. 87). O terceiro se refere à significação e ao sentido dos agentes que compõem as histórias que contamos uns aos outros, das provas que eles enfrentam, das aventuras que atravessam, dos tropos e dos gêneros que os organizam, das grandes narrativas que nos dominam infinitamente (ibidem, p. 87). O quarto fala do ser e desconstrói aquilo de que nos esquecemos quando nos preocupamos apenas com o ente, ainda que a diferença do ser esteja distribuída pelos entes, coextensivos à sua própria existência (ibidem, p. 87). Para Latour, a simetria consiste em perceber que tais repertórios somente são separados em um esforço ideal das mais diversas ciências e da filosofia, que constituíram o rol das disciplinas modernas que se distribuem entre a filosofia, as ciências naturais e as ciências humanas. Esses agentes são, para o autor, reais como a natureza, narrados como o discurso, coletivos como a sociedade, existenciais como o ser (ibidem, p. 89).

A simetria como princípio não se confunde com o relativismo, pois não se trata de estabelecer a relatividade de todas as culturas ou dos enunciados sobre determinadas realidades particulares e manter a natureza absoluta como árbitra das diferenças (daí a crítica de Latour ao multiculturalismo), mas de estabelecer relações entre os entes em seus modos de ser. A simples pergunta pelo que há não conduz a uma única resposta em termos 
ontológicos. O multiculturalismo, ou a dívida uma natureza/várias culturas (e seus rebentos, tais como relativismo, modernismo e pós-modernismo), pressupõem que os conflitos entre humanos, não importa quão distantes eles sejam, permanecem limitados a representações, imagens e ideias que diversas culturas podem ter de uma única natureza biofísica. Diferenças de opinião, desacordos e conflitos violentos teriam sua fonte na subjetividade da mente humana, sem que eles jamais envolvam o mundo, sua realidade material, sua cosmologia ou mesmo sua ontologia, as quais permanecem, por construção (ou pela natureza), intangíveis (LATOUR, 2002, p. 6). Em razão do acesso privilegiado do Ocidente à natureza e à sua já realizada unificação - e por conta disso, constituir-se como uma cultura privilegiada -, ele ocupa um lugar inquestionável como centro, sem que esse centro tenha um grupo étnico como sua origem. De acordo com Latour, isso é o que de fato habilita a diferença entre o "eles" - prisioneiros nos confins estreitos de suas próprias culturas e incapazes de apreender os princípios de unificação da natureza - e o "nós", que possui traços culturais mais ou menos enfatizados, mas cuja força oculta foi ter alcançado, graças à ciência, à tecnologia e à economia, por meio de um trabalho lento de erosão, o nível mais elementar da universalidade, o núcleo duro da natureza e o pano de fundo de qualquer história (idem, ibidem, p. 30). Apresenta-se uma "oferta generosa de deixar os outros entrar, sob a condição de que eles deixem à porta tudo o que lhes é caro: seus deuses, suas almas, seus objetos, seus tempos e seus espaços, em resumo, sua ontologia" (ibidem, p. 30).

Podemos notar, nessa breve inflexão do pensamento de Latour, os contornos políticos que a simetria assume. Afinal de contas, reconhecer a simetria traz implicações não somente na distribuição das ações entre humanos e não humanos como também entre humanos e aqueles humanos que, por conta dessa história, foram jogados para o lado de uma humanidade epifenomenal, cujos modos de ser e de configurar o mundo seriam, na melhor das hipóteses, crenças que deveriam ser respeitadas, desde que não ameaçassem as forças agregadoras e colonizadoras do ser. Se, no princípio da simetria, não há uma natureza absoluta, podemos falar que há multinaturezas ou um multinaturalismo, ideia cara a Viveiros de Castro, para quem o multiculturalismo ocidental é o relativismo como política pública, ao passo que o xamanismo perspectivista ameríndio é o multinaturalismo como política cósmica (VIVEIROS DE CASTRO, 1996, p. 120).

Juntamente com as ideias de perspectivismo interespecífico e alteridade canibal, o multinaturalismo forma os "três vértices de uma alter-antropologia indígena" (VIVEIROS DE CASTRO, 2015, p. 34). Perspectivismo e multinaturalismo se converteram, para além do seu terreno originário, em uma alternativa para pensar e colocar em crise nossos modos 
de articulação do discurso, especialmente ocidental, eurocêntrico e antropocêntrico. Se, na história intelectual do mundo ocidental ao Norte e ao Sul, optamos por usar somente nossos termos para avaliar outras ontologias e epistemologias, no caso de uma história intelectual do mundo ameríndio, ou seja, do multinaturalismo e do perspectivismo, o que temos é uma subversão dessa relação, que se torna simétrica com aqueles que sempre foram os outros exóticos favoritos de um discurso que fazia (e ainda faz) somente a alteridade do mesmo.

De acordo com o antropólogo, o perspectivismo é uma teoria ou um modo de pensar o pensamento indígena acerca do ponto de vista, de diversos povos do Novo Mundo, para os quais há uma concepção, com ligeiras diferenças entre uns e outros povos, segundo a qual o mundo é composto por uma multiplicidade de pontos de vista em que todos os existentes são centros potenciais de intencionalidade, que apreendem os demais existentes segundo suas próprias e respectivas características ou potências (VIVEIROS DE CASTRO, 2015, p. 42). No perspectivismo, o ponto de vista não cria o objeto, mas cria o sujeito: "será sujeito quem se encontrar ativado ou 'agenciado' pelo ponto de vista (idem, 1996, p. 126).

Como uma contraposição ao multiculturalismo, que se fundamenta na unicidade da natureza e na multiplicidade das culturas, o multinaturalismo, típico dos povos ameríndios, supõe uma unidade de espírito e uma diversidade dos corpos, ou seja, a "cultura" ou o sujeito seriam a forma do universal, enquanto a "natureza" ou o objeto, a forma do particular. Nas palavras do antropólogo, a etnografia da América indígena contém um tesouro de referências a uma teoria cosmopolítica que imagina um universo povoado por diferentes tipos de agências ou agentes subjetivos, humanos como não humanos deuses, animais, mortos, plantas, fenômenos meteorológicos -, todos providos de um mesmo conjunto básico de disposições perceptivas, apetitivas e cognitivas (VIVEIROS DE CASTRO, 2015, p. 43). A condição original comum aos humanos e animais não é a animalidade, como no evolucionismo, mas a humanidade (idem, ibidem, p. 46). "Se", continua o autor, "a condição comum aos humanos e animais é a humanidade, não a animalidade, é porque 'humanidade' é o nome da forma geral do Sujeito” (idem, 1996, p. 127).

Descola (1998, p. 27) chega a conclusões semelhantes em relação à forma geral de subjetividade - ou talvez fosse melhor dizer, traduz para nosso universo conceitual os modos como os intelectuais "de lá" pensam e configuram o mundo -, ao afirmar que os seres do cosmos se definem menos por uma essência abstrata ou por uma faculdade particular do que pelas posições que ocupam uns em relação aos outros. O referente comum às entidades que povoam o mundo não é o homem enquanto espécie, mas a humanidade 
enquanto condição (DESCOLA, 1998, p. 27). Há múltiplos existentes humanos em potencial que habitam o mundo, sem que a primazia caiba àqueles humanos como espécie tal como definimos em nosso universo ocidental. O devir ameríndio, se colocado nos termos de uma filosofia da história, tende a aniquilar não somente a direção evolutiva como também o sentido e a finalidade, sejam eles quais forem. Antes da pergunta pelo sentido do ser, cabe a pergunta pela posição do ser no cosmos/caos, posição que não está na representação, mas na coisa, no corpo. $\mathrm{O}$ animismo, como uma continuidade de almas e descontinuidade de corpos, dota plantas, animais e outros elementos de seus ambientes físicos de subjetividade e estabelecem com estas entidades todo tipo de relação pessoal, seja de amizade, troca, sedução, seja de hostilidade (idem, 2015, p. 13). Nestes sistemas animistas, humanos e muitos não humanos são concebidos como dotados de um mesmo tipo de interioridade, e por causa desta subjetividade comum é dito que animais e espíritos possuem características sociais: vivem em aldeias, seguem regras de parentesco e códigos éticos, desempenham atividades rituais e trocam objetos (idem, ibidem, p. 13).

Podemos verificar tais relações na etnografia que Descola (2006) faz dos Achuar, tribo jivaro da Alta Amazônia entre o Equador e o Peru: animais caçadores concorrentes dos homens; espíritos das florestas e das roças; pedras e amuletos poderosos; cães como interlocutores místicos; visitas inesperadas de Iwianch, o espírito de um morto que vagueia nos matos e nos pântanos; veados vermelhos que, às vezes, abrigam a alma dos mortos; o Amana, que encarna as aptidões da espécie em nível máximo, como de um macacobarrigudo; Tsunki, espíritos das águas, benévolos e respeitadores das etiquetas sociais. Esses são alguns dos diversos existentes que povoam as relações sociais que abrangem o universo. Como afirma Descola (2006, p. 256-257), na cosmologia jivaro a categoria mais englobante é a das pessoas, aent, que inclui todos os seres providos de alma (Wakan), ou seja, seres capazes de se comunicar já que dotados de intencionalidade e passíveis de serem afetados pelas mensagens endereçadas a eles: os humanos (em nossa convenção), plantas, animais, espíritos da floresta e do rio, certos objetos mágicos e mesmo profanos.

O animismo ao qual Descola recorre faz parte de um universo mais amplo de discussões sobre diversidade ontológica, o que faz com que os termos do debate acerca da ontologia, tão caros à filosofia, retomem certa força em outra seara do pensar, de um pensar que se atrela a modos de ser e de estar no mundo profundamente diferentes das cosmologias ocidentais. Descola sugere, pelo menos, quatro ontologias: animista, totemista, naturalista e analógica. A terceira parte de seu monumental Além da natureza e da cultura, intitulada As disposições de ser, é dedicada ao problema das ontologias: o animismo restaurado, o 
totemismo como ontologia, as certezas do naturalismo, as vertigens da analogia. $\mathrm{O}$ autor parte de uma distinção entre fisicalidade e interioridade para definir os modos como os existentes habitam o mundo. Seguindo a fenomenologia de Husserl, Descola afirma que "se os humanos tentassem experimentar qualquer forma de autoabstração abandonando a representação do mundo instituído e tudo que ele representa, o único recurso para autoavaliação que teriam disponíveis então seriam seus corpos e sua intencionalidade" (DESCOLA, 2015, p. 11), que o autor prefere nomear de "fisicalidade (no sentido de dispositivos que permitam a ação física) e interioridade (no sentido de autorreflexão)" (idem, ibidem, p. 11).

A uma possível crítica de que Descola esteja usando um modelo ocidental para pensar outros existentes no mundo, o autor antecipa que essa referência à fenomenologia não é mais um capítulo do esforço de pensar o mundo tendo como fiador de sentido o pensamento ocidental. Para ele, a fenomenologia não é mais do que uma resposta particular a uma disposição dos seres que aparece nos mais diversos agrupamentos humanos. $\mathrm{O}$ universal, neste caso, é o par fisicalidade-interioridade, cuja variação regional é a fenomenologia. O autor entende que "a despeito da diversidade conhecida de concepções da pessoa, noções de fisicalidade e de interioridade parecem estar universalmente presentes" (DESCOLA, 2015, p. 11). O antropólogo afirma a identificação como um mecanismo por meio do qual o "sujeito irá detectar diferenças e similaridades entre si mesmo e os objetos do mundo", através da "inferência de analogias e distinções de aparência e comportamento entre o que ele experimenta como característico dele mesmo e os atributos que atribui às entidades que o rodeiam" (idem, ibidem, p. 11).

De acordo com Descola, se as únicas ferramentas das quais dispõe o sujeito são sua interioridade e fisicalidade, "sua caracterização do mundo será baseada na atribuição ou negação seletiva destes atributos às outras coisas existentes" (DESCOLA, 2015, p. 11). As identificações possíveis, como se pode depreender do arranjo proposto por Descola, são limitadas: "quando confrontado com uma alteridade até então desconhecida, humana ou não-humana", o sujeito pode concluir: 1) que este objeto possui elementos de fisicalidade e interioridade análogos aos seus - totemismo; 2) ou que a interioridade e fisicalidade deste objeto são inteiramente distintas da sua - analogismo; 3) ou que este objeto possui uma interioridade similar e uma fisicalidade diferente - animismo; 4) ou que este objeto é desprovido de interioridade, mas possui um tipo similar de fisicalidade, o que em sua classificação é o naturalismo (idem, 2015; 2012). Estas fórmulas, de acordo com Descola, definem quatro tipos de ontologias, isto é, "sistemas de distribuição de propriedades entre 
objetos existentes no mundo, que em retorno fornecem pontos chave para formas sociocósmicas de associação e concepção de pessoas e não-pessoas” (idem, 2015, p. 11).

Na cultura ocidental, a prevalência dos arranjos entre os seres do mundo se dá, pelo menos desde o século XVII, pelo naturalismo. Em que consiste propriamente tal arranjo? Linhas acima apresentamos parte desse naturalismo, que coloca a ordem do mundo em uma natureza e em variadas culturas, cujos exemplos mais expressivos são o reducionismo e o multiculturalismo. A crença-chave da ontologia naturalista consiste em afirmar que os seres humanos são a única espécie que possui um equipamento psíquico capaz de originar diferenças culturais. O que diferencia os humanos dos não humanos é, segundo o naturalismo, "a consciência reflexiva, a subjetividade, o poder de significar, o domínio dos símbolos e a linguagem por meio do qual essas faculdades se expressam" (idem, 2012, p. 261-262).

A natureza como unidade foi, a partir do século XVII, algo que se tornou absoluto como regulador da ordem de todas as coisas, princípio para o qual a ciência e os conhecimentos nela inspirados deveriam convergir. Ou, como diz Krenak, "a metáfora da natureza que eles mesmos criaram para consumo próprio" (2019, p. 67). O naturalismo, nas palavras de Descola, "não é apenas a ideia de que a natureza existe, que certas entidades devem sua existência e desenvolvimento a um princípio que é estranho tanto à sorte quanto à vontade humana" (DESCOLA, 2006, p. 21). O naturalismo "implica uma contrapartida, um mundo de artifícios e livre-arbítrio, de complexidades que progressivamente emergem sob o escrutínio dos analistas" (idem, ibidem, p. 21), isto é, "a diversidade de expressões da criatividade humana na produção de signos, normas e produtos” (ibidem, p. 21). A fórmula naturalista é uma inversão da fórmula animista. A última faz prevalecer a universalidade da condição de sujeito moral e as relações entre humanos e não humanos autorizadas por ela, por sobre a heterogeneidade física das classes de existentes. A primeira subordina a sociedade humana e suas contingências culturais à universidade das leis da natureza (idem, 2012, p. 298).

\section{A cosmopolítica do sertão e Os sertões}

O que essas ontologias teriam a nos ensinar a respeito da obra Os sertões em sua condição de um coletivo de natureza, sociedade, linguagem e ser? Será que aquela condição de universalidade de sujeito moral que faz do pensamento ameríndio uma "cosmopolítica 
que imagina um universo povoado por diferentes tipos de agências ou agentes subjetivos deuses, animais, mortos, plantas, fenômenos meteorológicos" - pode ser encontrada na obra-mestra de Euclides? Não seria o sertão dotado de certas propriedades como espíritos, pedras e amuletos poderosos tais como eles existem para os Achuar?

Uma das razões que levou Euclides a afirmar que o sertão seria desconhecido por muito tempo não reside somente nos termos das classificações da natureza das quais os naturalistas não dispunham ou que não estava presente nas categorias geográficas de Hegel (CUNHA, [1902], 1985, p. 109; 128). Nossa hipótese é que podemos pensar Os sertões não somente através da tradicional divisão entre civilização e barbárie, ou Brasil superficial e Brasil profundo, ou sertão e litoral (o que todos já sabemos da obra de Euclides), como também através da mobilização de duas poderosas ontologias que se chocam e não se reconciliam na obra: a naturalista e a animista. Não há uma síntese nem uma sinédoque que unifiquem esses dois modos de habitar o mundo. Sua obra, publicada em fins de 1902, se tornou para alguns a expressão do pensamento determinista de fins do século XIX e princípios do século XX; para outros, o marco de inauguração - e de invenção (um conceito em voga nas teorias construtivistas) - do Brasil profundo. Aquém de um determinismo geográfico que coloca a agência natural no cerne de sua reflexão ou de um construtivismo linguístico que dá existência ao sertão somente a partir do jogo de significantes e significados (mononaturalismo e multiculturalismo de mãos dadas), parecem residir pontos de tensão que sugerem um coletivo de agentes na produção da obra Os sertões, especialmente o maciço sertanejo pensado por Euclides como um pensar a partir de e um pensar com diversos existentes que, em sua humanidade, não se restringiam às tropas do exército nem aos jagunços.

Os agentes humanos e não humanos que fazem a história que Euclides nos apresenta circulam de modo agonístico por essas ontologias, ora fazendo dos homens sertanejos uma extensão física da natureza, ora fazendo da natureza uma extensão anímica do sertanejo e dotada das mesmas intencionalidades e propriedades humanas que ele. Esta segunda perspectiva é a que nos interessa mais. Seria expressivo do primeiro caso a afirmação de Euclides ao referir-se aos jagunços como "inconstantes" como a natureza: "é natural que o seja. Viver é adaptar-se. Ela o talhou à sua imagem: bárbaro, impetuoso, abrupto" (CUNHA, [1902], 1985, p. 184). Uma natureza poderia talhar alguém à sua imagem, ou fazer da vida uma adaptação. Estaríamos diante de um exemplo típico do naturalismo se a natureza que "determina" o jagunço não fosse dotada de intenções. A natureza do sertão, diferente da natureza da mata, tem sua própria subjetividade - e ela é 
bárbara, impetuosa e bruta.

O "misticismo bárbaro" e o "animismo ingênuo" (CUNHA, [1902], 1985, p. 247) que penetravam a consciência do sertanejo acabaram por impregnar a obra de Euclides também. A integridade orgânica que opera na mesma fisicalidade manifesta-se não em uma natureza fria e indiferente ao homem, mas na caatinga como uma aliada do sertanejo que tem sua própria alma: “As caatingas são um aliado incorruptível do sertanejo em revolta. Entram também de certo modo na luta. Armam-se para o combate; agridem. Trançam-se, impenetráveis, mas abrem-se em trilhas multívias, para o matuto que ali nasceu e cresceu" (idem, ibidem, p. 277).

A mesma caatinga que afoga, agride e estonteia o viajante, "enlaça-o na trama epinescente e não o atrai; repulsa-o com folhas urticantes, com o espinho, com os gravetos estalados em lanças (ibidem, p. 118). Talvez seja esse o teor da gravidade que Euclides menciona ao comparar as teorias sobre as matas virgens enquanto "agente tático precioso" e o caráter das "caatingas pobres", às quais "cabe função mais definida e grave que às matas virgens" (ibidem, p. 277). As cesalpinas e as catingueiras, "plantas sociais" que "unem-se, intimamente abraçadas" e que "não podendo revidar isoladas, disciplinam-se, congregamse, arregimentam-se" (ibidem, p. 121). São essas plantas sociais, ou as relações sociais das plantas responsáveis por uma boa parte da ação conjunta com os sertanejos. O jogo de antíteses da natureza forma uma unidade mortal com os jagunços.

Ao trazer para o pensamento certas características do sertão que estão e são em sua condição de diversidade ontológica, o pensamento de Euclides não é tomado como um cogito que estende seus conceitos, suas formas e suas categorias para o mundo natural. A obra que se opera em Os sertões não deixa de ser, em parte, o próprio sertão como um agente intencional. Nesse sentido, arriscamos afirmar que, do mesmo modo que Euclides pode ser visto como o inventor dos sertões, os sertões e todos seus humanos potenciais podem ser vistos como coautores de Os sertões. Esse mundo, que se constitui desde a descrição e representação da terra, do solo, do clima e dos ventos, da hidrografia, da flora, do sol como inimigo, da caatinga, do mato doente (caatanduva), das cabeças-de-frade deselegantes e monstruosas, dos umbuzeiros como árvores sagradas e sócias fiéis dos vaqueiros, das seriemas de vozes lamentosas, das suçuaranas traiçoeiras, da flora agonizante, da luta, do arraial, do céu, das estrelas, dos canhões e dos armamentos, desvela-se como um emaranhado de entes que ocupam de modo constante e instável um espaço que ousamos nomear de cosmologia sertaneja, agentes do real que pedem passagem na obra.

A leitura que optamos por fazer de Os sertões é um pouco heterodoxa, pois ela implica que o pensamento seja pensado não como configurador exclusivo de mundo, mas 
como algo cujos limites são estabelecidos por diferentes existentes que circundam o autor, um contexto de emergência da obra em que as intencionalidades envolvidas não se restringem à intenção autoral, nem à sociedade que o condiciona. Talvez o cogito do sertão seja a intenção autoral. Quando sugerimos que em Os sertões há duas ontologias em disputa, pensamos que a distribuição dos existentes na agência histórica da guerra ora pende para o naturalismo, especialmente na concepção de um atraso dos sertanejos em relação à República (que não apresentamos aqui), ora para o animismo, quando certas disposições dos existentes se apresentam na espacialidade como um agente dotado de intenções. O devir da espacialidade atenua a distância no tempo, desafiando a régua temporal do evolucionismo e retirando dele, momentaneamente, sua autoridade. Se o tempo em parte separa, o espaço agrega. Mas agrega na luta, no conflito, na diferença entre dois mundos. No encontro do espaço sertanejo, há um tempo disjuntivo - o momento presente do conflito - que transforma o sentido do passado e do futuro da presença no presente. Dupla densidade, de espaço e de tempo, que operou na produção de Os sertões.

\section{Considerações finais}

A escolha da virada ontológica na antropologia como um exercício reflexivo que pode contribuir para pensar alguns termos da história intelectual tem a ver com a própria relação da história intelectual com esses modos de saber e com sua dificuldade de lidar com demandas de pesquisa que se ancoram fora das premissas do humanismo e, no quadro do humanismo, da própria virada linguística que fundamentou epistemologicamente uma boa parte da história intelectual. Não se trata de negar as conquistas da virada linguística, mas de explorar, na linguagem, certos elementos que têm um pendor mais realista do que propriamente idealista.

Seja como for, a história intelectual não precisa temer a perda de um mundo habitado. Se há um "problema da realidade”, é seu excesso e não a sua falta. Nessa tarefa de lidar com as coisas do mundo, a história intelectual pode desfrutar de certo pendor realista, ainda que não estejamos lidando diretamente com a "coisa em si" propriamente dita - ou talvez o problema seja exatamente pensar os termos do propriamente dito da coisa em si. Afinal, a história intelectual seria interessante se ela não lidasse com as coisas do mundo? Os usos que os historiadores fazem dos conceitos poderiam ter uma repercussão dotada de sentido e efetiva se tais historiadores não lidassem, de um modo ou de outro (ressalte-se o 
outro), com esse universo e multiverso de existentes que a todo o momento extrapolam os limites do pensamento? Seguramente, a resposta é negativa. E para que o pensamento tenha um alcance maior na história intelectual, torna-se imprescindível pensar esse pensamento por meio de uma espiritualidade fundada para além das premissas do humanismo.

\section{Referências}

ANKERSMIT, Frank. The Linguist Turn, Literary Theory and Theory of History. In: ANKERSMIT, Frank. Historical Representation, Stanford: Stanford Press, p. 29-74, 2001.

CARR, David. Experience and History: phenomenological perspectives on the historical world. Nova York: Oxford University Press, 2014.

CARR, David. Time, Narrative, and History. Bloomington/Indianapolis: Indiana University Press, 1991.

CLEMENS, Justin. Vomit Apocalypse; or Quentin Meillassoux's After finitude. Parrehesia, n. 18, p. 57-67, 2013.

CUNHA, Euclides da. Os sertões. [1902]. São Paulo: Brasiliense, 1985.

DESCOLA, Philippe. Estrutura ou sentimento: a relação com o animal na Amazônia. Mana, n. 4, v. 1, p. 23-45, 1998.

DESCOLA, Philippe. As lanças do crepúsculo: relações jivaro na Alta Amazônia. São Paulo: Cosac Naify, 2006.

DESCOLA, Philippe. Más allá de naturaleza y cultura. Buenos Aires: Amorrortu, 2012.

DESCOLA, Philippe. Além de natureza e cultura. Tessituras, v. 3, n. 1, p. 7-33, 2015.

KOSELLECK, Reinhart. Teoria da história e hermenêutica. In: KOSELLECK, Reinhart. Estratos do tempo. Rio de Janeiro: PUC/Contratempo, p. 91-109, 2014.

KRENAK, Ailton. Ideias para adiar o fim do mundo. São Paulo: Cia. das Letras, 2019.

LACAPRA, Dominick. Rethinking intellectual history: texts, contexts, language. Ithaca: Cornell University Press, 1983.

LACAPRA, Dominick. Understanding others: peoples, animals, pasts. Ithaca: Cornell University Press, 2018.

LATOUR, Bruno. Jamais fomos modernos. São Paulo: Ed. 34, 1994.

LATOUR, Bruno. War of the Worlds: What about Peace? Chicago: Prickly Paradigm Press, 2002.

RORTY, Richard. El giro lingüístico. Barcelona: Paidós, 1990. 
SÁ JÚNIOR, Luiz César de. Philippe Descola e a virada ontológica na antropologia. Ilha, v. 16, n. 2, p.7-36, ago/dez 2014.

SANTOS, Luis Henrique dos. Russell: vida e obra. In: RUSSELL, Bertrand. Ensaios escolhidos. São Paulo: Abril Cultural, p. VI-XX, 1978.

VIVEIROS DE CASTRO, Eduardo. Os pronomes cosmológicos e o perspectivismo ameríndio. Mana, n. 2, v. 2, p.115-44, 1996.

VIVEIROS DE CASTRO, Eduardo. Encontros. Rio de Janeiro: Beco do Azougue, 2008.

VIVEIROS DE CASTRO, Eduardo. Metafísicas canibais. São Paulo: Cosac Naify, 2015.

Submetido em: 30/08/2019

Aprovado em: 07/10/2019

Publicado: 15/12/2019

Notas

* Professor do Departamento de História e do Programa de Pós-Graduação em História da Universidade Federal de Santa Maria (UFSM). E-mail: carlos.armani@gmail.com

' O mesmo se pode dizer de Koselleck, especialmente em seu texto Teoria da história e hermenêutica, em que o historiador alemão procura apresentar certas condições meta-históricas de todas as historiografias possíveis (KOSELLECK, 2014). 